\title{
"No le pido a Dios otra cosa que me quite la vida antes que yo vea a los patriotas". Religión y miedo: las emociones de los ultimos defensores realistas (1818-1822).
}

\author{
"I do not ask God anything else but to take my life before I see the patriots."
} Religion and fear: the emotions of the last realist defenders (1818-1822).

\author{
David Fuentes Acuña \\ Magíster (c) en Historia, \\ Universidad Nacional Andrés Bello, Chile. \\ Contacto: Davidfuentes.ac@gmail.com
}

\begin{abstract}
Resumen
La resistencia realista existente en Chile desde 1818-1822, es un proceso poco abordado por la historiografía chilena. El énfasis de la etapa post-independencia ha estado centrado en el gobierno de Bernardo O'Higgins. Menos conocido es el impacto que tuvo la resistencia realista a nivel nacional y las emociones de estos hombres y mujeres que defendieron los últimos vestigios de la Monarquía al sur de América. Este trabajo estudia el miedo como la emoción más importante que sintieron los hombres y mujeres realistas, la cual estuvo combinada con fuertes asociaciones cristianas. Se describe, en un principio, la seguridad que el cristianismo entregaba a los fieles realistas en la resistencia. Luego se estudia el miedo divino que padecieron desde dos perspectivas: un miedo asociado a los patriotas como herejes y enemigos de la Monarquía y de la religión cristiana y, finalmente, un miedo interno y personal ante traicionar el sistema político elaborado por Dios.
\end{abstract}

Palabras claves: Miedo; Proclamas; Realistas; Religión; Ideología

\begin{abstract}
The royalist resistance, which has existed in Chile since 1818-1822, is a process little examined in Chilean historiography. The importance of this post-independence period has typically been centered on the government of Bernardo O'Higgins. Less well-known are the impact of the royalist resistance at the national level, as well as the emotions of these men and women who defended the last vestiges of the Monarchy in South America. This article examines fear as the most important emotion felt by the men and women of the resistance, a fear which was highly inflected with Christian ideas and meanings. The article first describes the security that Christianity provided to faithful royalists. Furthermore, it explores the divine fear that they suffered from two perspectives: on the one hand, a fear which was associated with patriots as heretics and enemies of the Monarchy and the Christian religion and, on the other hand, an internal and personal fear of betraying the political system as understood to be elaborated by God.
\end{abstract}

Keywords: Fear; Proclamations; Royalists; Religion; Ideology

David Fuentes Acuña,

"No le pido a Dios otra cosa que me quite la vida antes que yo vea a los patriotas". Religión y miedo: las emociones de los últimos defensores realistas (1818-1822), Autoctonía. Revista de Ciencias Sociales e Historia, Vol. I, N², Julio-Diciembre 2017, 269-283

ISSN 0719-8213 
David Fuentes Acuña, "No le pido a Dios otra cosa que me quite la vida antes que yo vea a los patriotas".

Religión y miedo: las emociones de los últimos defensores realistas (1818-1822).

Autoctonía. Revista de Ciencias Sociales e Historia, Vol. I, N²

La victoria obtenida por el bando patriota el 5 de abril de 1818 en la batalla de Maipú, trajo a los revolucionarios un futuro esperanzador para la conformación del nuevo Estado republicano. Las tropas realistas estaban derrotadas y en el pensamiento de los vencedores era casi imposible el surgimiento de un nuevo foco de resistencia armada.

Tras la derrota, la mayoría de los sobrevivientes soldados realistas se convirtieron en prisioneros de guerra, siendo ejecutados o forzados a trabajar en labores estatales. Solo la minoría de ellos será perdonada para incluirse en las fuerzas patriotas por su condición de veteranos.

El bando patriota realizaba esta acción sabiendo que los soldados realistas retrocedían al sur de Chile para engrosar las filas monárquicas, por lo que ejecutando, forzando al trabajo o integrando a los sobrevivientes más experimentados, se detendría ese éxodo a la provincia de Concepción.

A pesar de los mecanismos de represión realizados por las fuerzas patriotas, un importante número de soldados realistas abandonaron la zona central para trasladarse a la provincia de Concepción con la esperanza de encontrar abrigo y refugio. Al llegar, se encontraron con un buen número de fieles realistas organizados bajo el mando de Vicente Benavides, líder de la resistencia monárquica. La premisa para él y sus tropas era muy sencilla: mediante una guerra de guerrillas, había que complicar a toda costa el establecimiento de las fuerzas patriotas en el sur del país.

Mientras tanto, la Provincia de Concepción presentaba una imagen sumamente triste debido a la guerra de la independencia. Según palabras de Ramón Freire, la ciudad exhibía “...un espectáculo bien triste; pues los enemigos han arrancado hasta las rejas de hierro de las ventanas de muchas casas"1. John Coffin, un viajero norteamericano que se encontraba apresado en la provincia, agregará que los patriotas “...han dejado huellas de su paso por todas partes; cargaron con cuanto mueble de valor encontraron y los que no se consideraron dignos de llevarse, los quemaron o rompieron" (Coffin, 1898: 73).

Es un escenario de desolación como el existente en la Provincia de Concepción, más la espera de la futura arremetida patriota que se esperaba en el sur del país, los fieles realistas se organizaron en un escenario lleno de inseguridades. Sin embargo, tanto mapuches, clérigos, campesinos y españoles, tenían un punto en común: la defensa del Rey de España.

Importante en la organización del ejército fueron los clérigos, quienes, mediante la creación de proclamas, elaboraron un discurso en el que sostener la causa realista, era participar en una lucha divina que mantuviese en el territorio sureño un sistema creado por Dios.

La "Guerra a Muerte", término establecido por Benjamín Vicuña Mackenna en su obra (1972), se caracteriza por ser un proceso histórico en donde el saqueo de haciendas, el incendio de pueblos y el fin de los códigos de guerra son los protagonistas del conflicto. Puntualmente, la historiografía chilena ha enfatizado en las concepciones negativas de los defensores realistas, centrándose en aspectos perjudiciales (Vicuña Mackenna, 1972; Barros Arana, 1850) 2 que perduran hasta nuestros días (en particular por la caracterización sobre Vicente Benavides, líder de la resistencia sureña) (Barros Arana, 1850: 419; Vicuña Mackenna, 1972: 35; Salazar, 2011: 504), existiendo poca atención hacia este proceso histórico. En su mayoría, toma preponderancia el estudio del gobierno de O’Higgins y, también, el énfasis en trabajar aspectos relacionados a "lo chileno" en desmedro de "lo español", visto esto como un elemento poco llamativo o que no produjo consecuencias importantes post-independencia dignas de estudiarse (Collier, 1977: 218; Barros Arana, 1892: 8).

Contrario a lo anterior, buscamos aportar en el estudio de los defensores realistas que resistieron en la Provincia de Concepción desde la Historia de las Emociones, centrándonos en las inseguridades que padecieron estos fieles al ver fracasar, poco a poco, un sistema con más de tres siglos de permanencia en América.

Creemos que estos soldados realistas padecieron miedos asociados a la religión, debido a que defender el sistema monárquico, era lo mismo que sostener la causa de Dios. Ante eso, surgieron diversos discursos e imaginarios contra todos aquellos que intenten unirse a las fuerzas patriotas o traicionar a la Monarquía. Específicamente, los chilenos son caracterizados como pecadores, mientras que los 
David Fuentes Acuña, "No le pido a Dios otra cosa que me quite la vida antes que yo vea a los patriotas".

Religión y miedo: las emociones de los últimos defensores realistas (1818-1822).

Autoctonía. Revista de Ciencias Sociales e Historia, Vol. I, N²

traidores al Rey, son condenados a las penas del infierno.

Este ejercicio pudo ser posible gracias a los clérigos realistas, quienes elaboraron proclamas en contra de patriotas y traidores realistas. Como dominadores del discurso religioso cristiano $\mathrm{y}$, guerreros en varias ocasiones, los clérigos se movían por la provincia en busca de adherentes a la causa, leyendo las proclamas en cada pueblo que visitaban. Esta propaganda provocó en los realistas la siguiente disyuntiva: si desertamos a la corona, tendremos el castigo divino por abandonar el sistema que Dios ha impuesto en la tierra personificado en el Rey, pero si nos acercamos a los patriotas, nos relacionaremos con los pecadores, sujetos revolucionarios que buscan romper el orden divino.

En ese sentido, las proclamas realistas, elaboradas por sacerdotes cercanos a los altos mandos de la resistencia de la corona, fueron un mecanismo de amarre ideológico para las personas sureñas cercanas a la fidelidad del Rey, provocando más que un miedo militar producto de la guerra, un miedo religioso ante imaginarios creados en los discursos de las proclamas.

Con lo dicho, en esta investigación nos preguntamos, ¿Cómo y en qué sentido se desarrollaron los miedos? ¿Cuáles fueron sus variaciones? ¿En qué grados se desarrolló el miedo al fracaso monárquico? ¿Cómo se expresan los miedos divinos en referencia a las fuerzas patriotas?

Nuestra investigación se centra en tres etapas. Primeramente, la fidelidad realista vista desde la seguridad, ya que, como existe miedo a que fracase el sistema monárquico por ser la causa justa de Dios, la religión cristiana -fundamentada en las proclamas- se transforma en la seguridad para los fieles de la corona, por lo que aceptar la propaganda es reconocer las propias inseguridades como grupo (mapuches y campesinos) que la Monarquía logra solucionar. Es importante entender todas las simbologías que asociaban a la religión católica con el sistema monárquico, teniendo presente que, como señala Jan Plamper, (Plamper, 2014) algunas emociones se han perdido o ya no existen, teniendo muchas especificidades según el momento al que le prestemos atención. Por lo mismo, al explicar la seguridad que se tenía del rey español católico, es vital advertir la fidelidad dentro del contexto de guerra que estudiamos.

Para pasar de la seguridad cristiana-monárquica a las inseguridades relacionadas a los patriotas como pecadores y enemigos de la religión, es importante centrarnos en el miedo como un afecto que, según Mabel Moraña (2012), debe ser visto desde una perspectiva social que se asocia a una crítica propia de los cambios culturales e históricos del contexto a estudiar. Es decir, pasar de la seguridad a la inseguridad, es lógico si se entiende dentro de la fase final de la independencia, visto el miedo como una dinámica que se mueve según el momento del grupo determinado. Por eso, en la segunda etapa de la investigación, estudiamos las caracterizaciones religiosas con las que se asociaban a los patriotas, concepciones ligadas, principalmente, al pecado y la herejía. Aquí el miedo lo analizamos según Aristóteles, (Domínguez, 2003) quien lo define como "...una aflicción o barullo de la imaginación (phantasía) cuando está a punto de sobrevenir un mal destructivo o aflictivo". Muchas de las concepciones negativas que cayeron sobre los patriotas, fueron fundamentadas por las proclamas realistas, inventando en algunos casos, estereotipos negativos que afirmaban que los chilenos destruirían el sistema divino, siendo una manifestación extrema del miedo. Como los curas de la provincia buscan defender a toda costa la causa divina, el contacto con los patriotas es un mal que se debe evitar a toda costa.

En relación a esto, Jean Delumeau señala que la interacción con cualquier objeto que produzca miedo, puede expresarse como:

“...una emoción de choque, a menudo precedida de sorpresa y causada por la toma de conciencia de un peligro inminente o presente. Advertido, el organismo reacciona con comportamientos somáticos y modificaciones endocrinarias que pueden variar mucho según las personas y las circunstancias" (Delumeau, 2002).

Es decir, el miedo constituye una situación espontánea de peligro en donde el ser humano se prepara para evitarlo como algo natural. Nosotros pondremos atención a las respuestas de los hombres y mujeres realistas ante el contacto con las fuerzas patriotas, en donde muchos de ellos, no dudarán si los patriotas son buenos o no, simplemente se 
David Fuentes Acuña, "No le pido a Dios otra cosa que me quite la vida antes que yo vea a los patriotas".

Religión y miedo: las emociones de los últimos defensores realistas (1818-1822).

Autoctonía. Revista de Ciencias Sociales e Historia, Vol. I, N²

bloquearán o responderán deseando la muerte, siendo elementos propios de lo que representa el miedo.

En la tercera parte, vemos el miedo que padecían los realistas en el caso de no defender la causa real, siendo miedos ligados al castigo divino y al fracaso del sistema establecido por Dios en la tierra. Aquí, aferrándonos de Maximiliano Korstanje (2011), definimos el miedo como un sentimiento humano de supervivencia, por lo que luchar en favor del rey permite sobrevivir frente a la adversidad por ser una defensa religiosa.

En estos puntos serán importantes los análisis de Bauman (2008) en relación al miedo, quien señala que estos se fortalecen con mayor fuerza en contextos de temores. Así, el proceso independentista produce miedos que derivan desde mucho antes en las personas pero que se fortalecen en el momento, sabiendo, sobre todo los defensores del Rey, que están en la última etapa de su lucha. Tanto el miedo a un castigo divino como al fracaso del sistema monárquico efectuado por las fuerzas patriotas, toman fuerza en el instante, pero existen en los sujetos desde los inicios de la guerra. En este punto vale destacar las proclamas realistas como un mecanismo de control social que establece un trauma psicosocial, que según Ximena Faundez y Marcela Cornejo (2010), sirven como un elemento de control que amedrenta y regula el orden como un elemento de represión.

Para nuestro trabajo utilizaremos fuentes provenientes del Archivo Nacional y la memoria del viajero norteamericano John Coffin (1898) titulada: Diario de un joven norte-americano detenido en Chile durante el periodo revolucionario de 18171819.

Las proclamas realistas son las que reflejan los discursos que buscan atemorizar y motivar a la población, llenos de conceptos religiosos ligados a la defensa del sistema monárquico. Para verificar los resultados de la propaganda religiosa, contamos con comunicaciones de fieles realistas, más la memoria de Coffin, que nos permita encontrar inseguridades que podamos, posteriormente, relacionar al discurso producido en las proclamas. Considerando lo que postula Robert Philippe (2006), entendemos que en el análisis de todo discurso, la inseguridad surge y se percibe como una ausencia de seguridad, por lo que el sentimiento del miedo se origina cuando nos sentimos expuestos al riesgo. De esa manera, desde las proclamas, que destacan las seguridades e inseguridades religiosas que entrega la defensa del Rey, intentaremos conocer los miedos religiosos de los fieles monárquicos.

\section{1. "Obraban impulsados por el mismo afecto a la causa del Rey". La fidelidad al lejano rey español.}

La defensa realista contó con hombres y mujeres que lucharon en defensa de la causa justa de Dios y del rey. Para ellos, unirse a la resistencia monárquica, era sostener el sistema o el orden tradicional de las cosas (Hobsbawm, 2001; Contador, 1998; León, 2010).

La resistencia contó con campesinos, mapuches $\mathrm{y}$ milicianos chilenos y europeos que reflejaban sus marcadas diferencias culturales. Como señala John Coffin, todos ellos se encontraban “...casi desnudos, muchos de ellos pintados y desfigurados de la manera más repelente, armados con lanzas de cerca de veinte pies de largo y todos montados en magníficos y bien amaestrados caballos" (Coffin, 1898: 183). Más allá de las diferencias en sus formas de vida, en ellos primaba el apego “...a la religión, a la sumisión como un orden natural y respeto al lejano soberano español" (Contador, 1998: 47).

Como eran tiempos de guerra en donde la Monarquía tenía la desventaja, sus fieles buscaron aferrarse a elementos que les permitiesen obtener mejores expectativas, apareciendo las asociaciones religiosas, como un premio al esfuerzo de lo vivido terrenalmente. La defensa realista llevó al florecimiento de afectos que conectaron a los fieles con el Rey y con Dios, siendo una triple asociación que, en el caso específico de los sujetos de la provincia de Concepción, inundó de esperanzas sus vidas. Lo interesante, es que independiente de la unión afectiva entre los fieles realistas y el Rey, cada uno de ellos tuvo sus propias pretensiones para preferir a la corona, debiéndose a que, como señala Mabel Moraña, los afectos son difíciles de englobar en conjunto porque "...cada persona ya sea en su pensamiento $u$ acciones del día a día, piensa 
David Fuentes Acuña, "No le pido a Dios otra cosa que me quite la vida antes que yo vea a los patriotas".

Religión y miedo: las emociones de los últimos defensores realistas (1818-1822).

Autoctonía. Revista de Ciencias Sociales e Historia, Vol. I, N²

diferente según las emociones y pasiones vividas" (Moraña, 2012: 324).

Tanto mapuches, españoles o campesinos, percibieron sus afectos al Rey desde diversas perspectivas grupales, relacionadas únicamente en la seguridad que la imagen real delegaba en tiempos de guerra. Imagen que, los altos mandos realistas, supieron aprovechar para fomentar el reclutamiento a las filas del ejército.

Los mapuches fueron uno de los más acérrimos defensores de la corona y, según John Coffin, “... bastaba señalarle o nombrarles un patriota para que cayeran sobre él con todo el furor salvaje de su odio" (Coffin, 1898: 182). Esto se debió a que, como señala Bengoa, los españoles “...habían dado pruebas luego de todos los parlamentos, que no deseaban entrar y quitar el territorio araucano" (Bengoa, 1985: 83). Pensamos que existe un procesamiento analítico por parte de los mapuches para defender a la corona, producto del contexto propio de la guerra. Después de 1818, este grupo debe pensar y elegir muy bien el bando que seguirán en el sur, sabiendo, sobre todo, que la resistencia realista se ubica en la Provincia de Concepción. Lo seguro, es que percibieron la seguridad en la Monarquía gracias a los parlamentos del pasado, los que les hicieron comprender como grupo, que poseían una mayor relación de confianza con el Rey. Como afirma el viajero sueco Carlos Bladh, los españoles “...ya no usurpan el territorio de los indios, y han aceptado la política de mantener la verdad y la ley, conservando amistad con ellos mediante regalos anuales" (Bladh, 1951: 69).

Por otra parte, los campesinos demostraron todo el afecto a la Monarquía y la fidelidad cristiana al momento de ser llamados al servicio activo. Estos:

"Obraban impulsados por el mismo afecto a la causa del Rey, parecían ajenos a un peligro inmediato y se manifestaban confiados en el éxito final. Resultaba, en efecto, que se consideraba entre ellos como moralmente imposible que combinación humana alguna pudiese por mucho tiempo resistir el poder y la voluntad del Rey muy católico" (Coffin, 1898: 198).
Este grupo considera "moralmente imposible" la derrota del Rey porque existe una confianza total hacia el poder divino, el cual maneja los hilos de la guerra a favor de la corona. Por lo demás, los campesinos de la época se caracterizan por tener vidas miserables, así que Dios aparece como una respuesta ante la miseria. Sobre esto, Bladh afirma que los campesinos "son sufridos y pacientes en el trabajo, valientes en la guerra y crueles contra sus enemigos; pero son hospitalarios con el extranjero que les visita para asuntos pacíficos, y su hospitalidad es segura". (Bladh, 1951: 203). En ese sentido, si los campesinos trabajan de manera difícil, la seguridad eterna en un contexto de guerra en donde pueden perderlo todo, es abrazar la lucha monárquica.

De esa manera, campesinos e indígenas abrazan la causa real desde una especie de ceguedad ideológica porque, más allá de lo que puedan reflexionar o percibir de los patriotas como objeto del miedo e, inclusive, independiente de sus propias pretensiones, la seguridad que entrega la figura real es la eternidad transmitida por Dios. Es entendible esta situación porque hablamos de tiempos de guerra, en los cuales el miedo a la muerte es presente y constante. Timmermann afirma que en momentos de conflictividad social:
“...la ideología es una noción que puede ser validada por su aspecto objetivo, es decir, en relación con la experiencia, pero también puede serlo por su aspecto subjetivo, por su fuerza persuasiva, por su utilidad social, tanto para el que la produce como para el que la acoge. En este sentido, la ideología dirige una acción social” (Timmermann, 2005).

La ideología monárquica, llena de conceptos divinos, tuvo dos utilidades sociales. La primera consiste en la tremenda seguridad en la mentalidad de sus fieles, sintiéndose parte de una acción conjunta que hizo rechazar todas las promesas de los patriotas. La segunda, permitió fortalecer los verdaderos objetivos que tenían los líderes realistas con la masa campesina e indígena, los cuales eran, únicamente, utilidad social de soldados de guerra.

Por ejemplo, las proclamas patriotas apelaban a que no establecerían ningún castigo a los realistas, protegiéndolos y dándoles la opción de retirarse al lugar que ellos determinen conveniente: 
David Fuentes Acuña, "No le pido a Dios otra cosa que me quite la vida antes que yo vea a los patriotas".

Religión y miedo: las emociones de los últimos defensores realistas (1818-1822).

Autoctonía. Revista de Ciencias Sociales e Historia, Vol. I, N²

“Todo militar y paisano, que no siendo habitante de Chile, se pasase del dominio del enemigo a nuestro ejército y provincias, después de ser atendido conforme a su mérito y grado, tendrá la libertad de restituirse a España o a cualquier Estado, o provincia extranjera, o de América..."

Sin embargo, esas proclamas entregaban seguridades momentáneas, pero no llenaban el vacío de la eternidad cristiana de los fieles realistas. A diferencia de los discursos patriotas, los sacerdotes monárquicos en su propaganda apelan a que su lucha es la más justa que existe sobre la tierra, porque cuentan con “...los apoyos más sólidos, más justos, y más firmes que nos acreditan deber de los reyes su autoridad al altísimo por cuanto reciben del mismo Dios su poder"

En cuanto al segundo punto, Vicente Benavides ordenó en sus instrucciones a sus subalternos (entre los que se cuenta el cura Juan Antonio Ferrebú, su mano derecha) como unas de las tareas más importantes, que se trate “...con la mayor afabilidad a toda la pobrería y gente de campaña de quienes podemos conseguir grandes ventajas" 5. Es decir, hay que encantar a la masa campesina para que pelee en favor del Rey, sabiendo el gran provecho religioso que consiguen de ellas.

De esa manera, la utilidad social que tuvo la ideología monárquica en sus fieles fue tremenda para continuar la resistencia en el país. Pintada de seguridad, fue un elemento de lucha frente a los patriotas y, también, de control en favor de los altos mandos monárquicos.

Esa ceguedad ideológica se reflejó en casos como los relatados por Coffin, en donde describe el encuentro con un amigo tras perderse en la provincia:

"Se sorprendieron muchísimo cuando me vieron. Ignoraban no solamente que yo me hallaba en Concepción, pero ni siquiera tenían idea de que pudiera hallarme con vida. Se creía en Penco que había sido asesinado y abandonado en la montaña la noche que salimos de allí. Esto nacía probablemente de la muerte de un joven patriota que fue ultimado en aquellos alrededores pocos días antes por la misma guerrilla, por haber hecho alguna resistencia y negádose a gritar "Viva el Rey" (Coffin, 1898: 229).
La causa monárquica como apego a la tradición cristiana, llevó a que todo enemigo fuese destruido por oponerse a su causa. Importantes en dicha tarea fueron los curas realistas quienes, mediante una importante tarea de propaganda religiosa, pregonaron pueblo en pueblo el discurso cristiano. El sacerdote Juan Antonio Ferrebú fue la mano derecha de Benavides y uno de los principales organizadores de este discurso.

Beauchef en sus memorias expresó cómo sufrió el ataque por parte de indígenas realistas mediante la propaganda religiosa, afirmando que será un tal cura "Palacios quien los sublevó contra nosotros (...) Está asociado con un fraile misionario español diabólico quien vive con los indios. (Fraile franciscano Salvador Racela)" (Puigmal, 2005: 148).

Se expresa que la propaganda religiosa fue aceptada por los defensores realistas y masificada por los curas, asociando a los patriotas como enemigos de la religión. Las proclamas realistas trajeron tan buenos resultados, que Ramón Freire le expresará a O'Higgins, con un tono amenazante, que:

"A la mayor brevedad posible, venga el mayor número de caballería de la otra parte del Maule, pues debe V.E. persuadirse que la provincia se levanta en masa, siendo destrozada mi fuerza de caballería, quedando solo en esta ciudad alguna milicia" 6 .

Si la provincia se levanta en masa, es lógico pensar que los altos mandos realistas aprovecharon las proclamas para fomentar aún más la participación de un territorio con muchos adherentes a su causa. Sobre esta problemática situación para los patriotas, Ramón Freire informará al gobierno central, que las proclamas realistas son, inclusive, necesitadas por la población y no existen manera de detenerlas:

"En el día apetecen y solicitan estos papeles hasta la gente de los campos; a mí me los han pedido pero no he tenido ninguno que poderles franquear. Este es un mal que debe remediar el gobierno"

$\mathrm{Si}$ los campesinos apetecen las proclamas realistas, bien pudieron servir estas últimas como discursos bíblicos. La propaganda monárquica se encuentra llena de conceptos, asociaciones y citas de la misma Biblia, siendo una expresión de la seguridad religiosa de los fieles de la corona en Chile. 
David Fuentes Acuña, "No le pido a Dios otra cosa que me quite la vida antes que yo vea a los patriotas".

Religión y miedo: las emociones de los últimos defensores realistas (1818-1822).

Autoctonía. Revista de Ciencias Sociales e Historia, Vol. I, N²

2. "Se extremecían solo ante la idea de recibir salvaguardia y protección de manos de los enemigos de su Rey". Los patriotas y su enemiga caracterización de la fe católica.

Los patriotas fueron reflejados como pecadores y enemigos de la religión católica, idea favorecida gracias a las proclamas realistas que fortalecieron la resistencia monárquica al elaborar un discurso perjudicial sobre los revolucionarios. Esta concepción negativa fue fundamentada por los actos realizados por los patriotas, tales como los reglamentos que San Martin elaboró para castigar a los soldados que vayan al sur del país a enrolarse en las fuerzas realistas:

"Se les hará entender a los oficiales prisioneros que por cada uno que se fugue, se echarán suerte entre todos para que uno de ellos vaya a trabajar a la maestranza con cadena (...) que todo oficial que se fugue y sea aprehendido, será pasado por las armas inmediatamente" 8 .

Esas noticias llegarán a oídos de los realistas gracias a sus espías, apelando en sus proclamas, al duro escarmiento que los fieles monárquicos podrían recibir de los revolucionarios ante todo contacto. Esto será muy bien utilizado en sus discursos, señalando Coffin, que la propaganda realista realizada por los curas, señalaba a la población:

“...que la guerra se había convertido entonces en una lucha de exterminio y que si los patriotas vencían no habían de dar cuartel a nadie, ni aún a los más infelices. Muchos del populacho de Talcahuano, que tan a menudo había resultado ser la piedra de esquina de los patriotas, se hallaban reunidos aquí (San Pedro), creyendo que ellos, menos que nadie, tenían motivos para esperar perdón y reconciliación" (Coffin, 1898: 217).

De esa manera, las proclamas tenían el objetivo de plasmar a los patriotas como enemigos de todo sujeto que defiende la causa del rey, pero también, plasmaron la idea de que la lucha realista es una defensa divina y cristiana. El cura Juan Antonio Ferrebú, al momento de brindar un discurso a los habitantes de Rere para que se integren a la lucha monárquica, señala que los patriotas “...han quitado la vida tan ignominiosamente hasta llegar al extremo que ese ilegítimo e intruso cura de Gallardo, ese sacerdote apostata les haya negado los sacramentos olvidandose este sacrílegio del ejemplo de Cristo"9. De esa forma, el cura realista busca expresar a la población de Rere, que ellos son los únicos que siguen los sacramentos cristianos y que los patriotas los abandonan, transformándose así, en enemigos de la fe católica.

Los revolucionarios tendrán presente el discurso pecador que cae sobre ellos, afirmando que esto se debe al "...terror que estudiadamente les infundían los enemigos, pintando a nuestras tropas como una gavilla de asesinos feroces que todo lo asolaban"10. Ramón Freire, afirmó que sus proclamas no tienen la aceptación que esperan debido a "la mezquindad con que siempre han corrido en esta provincia, creo que ha dado lugar en parte a la obstinación con que se han mantenido muchas personas"11.

El ejemplo más claro del rechazo a las amnistías patriotas será otorgado por John Coffin, quien menciona en sus memorias, que dos soldados desertores del ejército realista llegaron donde la familia en la cual este se cobijaba, mostrándoles una proclama del Director Supremo, en la cual se señala la protección y el regreso de todas sus antiguas propiedades.

"Sin embargo, la decisión final adoptóse con extrema hesitación por parte de la señora $y$ de varios otros de la familia, quienes se extremecían solo ante la idea de recibir salvaguardia y protección de manos de los enemigos de su Rey" (Coffin, 1898: 226).

Como los patriotas saben que existe un discurso contrario hacia ellos, caracterizado por asesinos y pecadores, cualquier contacto con las fuerzas chilenas por parte de hombres o mujeres fieles al Rey, traerá el surgimiento de nervios y ansiedad. Delumeau señala que una de las características extremas del miedo, se expresa cuando el organismo reacciona:

“...con comportamientos somáticos y modificaciones endocrinarias que pueden variar mucho según las personas y las circunstancias: aceleración o reducción de los latidos del corazón; respiración demasiado rápida o lenta; contracción o dilatación de los vasos sanguíneos; hiper o hiposecreción de las glándulas; inmovilización o exteriorización 
David Fuentes Acuña, "No le pido a Dios otra cosa que me quite la vida antes que yo vea a los patriotas".

Religión y miedo: las emociones de los últimos defensores realistas (1818-1822).

Autoctonía. Revista de Ciencias Sociales e Historia, Vol. I, N²

violenta; y, al límite, inhibición o al contrario, movimientos violentos y incontrolables" (Delumeau, 2002: 9).

El nerviosismo de la familia realista y el miedo existente ante la traición de integrarse a las fuerzas patriotas, demuestra una inseguridad que se reprimió de una manera ideológica. Todo contacto con los patriotas es una incertidumbre, ya sea asociada a la destrucción o protección de sus bienes, por lo que la inseguridad se basa en una falta de confianza producto de una ideología predominante. Eso no quita el hecho de que el contacto con los patriotas, más que ser un acto de guerra, es un hecho del cual los realistas deben alejarse, con el que no pueden tranzar, dialogar, ni confiar.

María Casilda Ortega, en relación a este miedo de enfrentarse con los patriotas, demostrará que, a pesar de ir perdiendo la guerra, por nada del mundo se debe traicionar al Rey para sobrevivir. Eso sería caer en el pecado y las penas del infierno, por lo que la muerte se convierte en una escapatoria de todas las inseguridades terrenales, transformándose prácticamente en un regalo divino:

"Pero según veo; y las noticias q.e bienen de Lima no son muy buenas; ya querrá Dios a cabar con nosotros porq.e ya se habrá llenado la medida con nuestros pecados. No le pido a Dios otra cosa q.e me quite la vida antes que yo vea a los patriotas" 12 .

El solo hecho de enfrentarse con los patriotas provoca un miedo terrible en María Casilda Ortega, demostrando el poder de la ideología monárquica. El miedo es factual, expresándose como afirma Korstanje, en “...una emoción básica sujeta a un objeto limitado, distinguible en tiempo y espacio cuya función principal es darle al organismo (animal o humano) una rápida respuesta frente a un peligro dado" (Korstanje, 2011: 1). Como el temor actúa, según Kostanje, en el presente y en una acción determinada, pone al sujeto al límite, viendo a la muerte como salvación para escapar del objeto del miedo. Para Casilda Ortega, el anhelo de su muerte es visto como un escape del miedo de lo temible que es enfrentarse a las fuerzas patriotas, fundamentada por las concepciones monárquicascristianas señaladas en las proclamas.

El tema de la muerte como escapatoria es interesante, porque para María Ortega, más que una salvación, también demuestra que pierden la guerra por culpa de los pecados. Sin embargo, ¿dónde está la seguridad de la victoria terrenal? No existe. Ella simplemente no quiere relacionarse con los enemigos de su Dios. La victoria, en este caso, se encuentra en el cielo, no en la tierra.

En relación a la muerte, Bauman señala que:

"Solo la muerte significa que nada ocurrirá a partir de entonces, que nada le ocurrirá a usted, es decir, que nada sucederá que usted pueda ver, oír, tocar, oler, disfrutar o lamentar. Por eso la muerte seguirá siempre siendo incomprensible para los vivos" (Bauman, 2008: 46).

Como la muerte permite no sentir nada ante el encuentro con el objeto del miedo, la muerte se transforma en una seguridad terrenal para transformarse en una salvación eterna, ya que es un elemento de escape de la desconfianza patriota. Las proclamas, en ese sentido, lograron su objetivo y, como afirma Timmermann en relación a la publicidad y las emociones que provoca, "los que más tienen sentimiento de inseguridad son también los que más se alimentan de este tipo de mensajes y aceptan de buen grado la confirmación de los medios de comunicación" (Timmermann, 2015: 23). Por lo mismo, ese sentimiento de inseguridad de los realistas, ante el fracaso del sistema divino y de terminar muriendo por esa causa, encuentra esperanza en discursos que apelan al poder de Dios personificado en el Rey. Para Carlos Page, en las proclamas:

"El protagonista siempre será el Rey, que aunque ausente en las remotas tierras de ultramar, delegaba su autoridad en los representantes locales, que tomaban su papel ostentando el lujo y pompa propios de la realeza, produciendo un deslumbramiento en el pueblo que marcaba las jerarquías establecidas" (Page, 2004: 78).

Son dichos representantes locales, en este caso sacerdotes y oficiales importantes, los que tienen la tarea de motivar a los realistas en continuar la batalla. Así, el mensaje adquiere una validez en donde los medios de comunicación basados en las proclamas, dan sentido a todos los ideales religiosos con los que se critica a los patriotas y, de manera paralela, se intenta mantener concentrados ideológicamente 
David Fuentes Acuña, "No le pido a Dios otra cosa que me quite la vida antes que yo vea a los patriotas".

Religión y miedo: las emociones de los últimos defensores realistas (1818-1822).

Autoctonía. Revista de Ciencias Sociales e Historia, Vol. I, N²

a los defensores del Rey. Por ejemplo, el cura Ángel Gatica señala tras los triunfos realistas en Tarpellanca y Pangal en 1820:

"No dudáis queridos hijos, los motivos justos que me obligaron asepararme de vosotros; poderosos fueron ciertamente porque aunque la obligación de Parroco por una parte exigia en mi el cuidado de vuestras almas; por otra miraba claramente el riesgo aque me exponia si me quedaba entre vosotros. Conocia sin duda alguna, que si caia en manos de los enemigos, sufriria todos aquellos vejamenes e insultos que son propios del iniquo proceder de los rebeldes.

En presencia de ello no dejareis de acordaros con cuanta ignominia con cuanta temeridad $\mathrm{y}$ en el termino preciso de veinte yquatro horas, me hicieron salir de mi casa y caminar desterrado ala otra banda del Maule, y solo por un efecto de la providencia, pude conseguir el quedar en la tella del parral (...) Todo esto ala verdad me hiso temer y teniendo presente lo que Jesu-Cristo nos aconseja por san Mateo en el capitulo 10, q.to, nos dice que si nos viesemos perseguidos en una ciudad nos separemos de ella huyendo a otra resolvi salir de mi pueblo abandonandolo todo antes de ser victima del fuego de los rebolucionarios"13.

Así como María Casilda Ortega ve la muerte como escape, Ángel Gatica huye de Chillán para no enfrentarse con los patriotas. Nuevamente, todo el miedo al contacto con los chilenos se debe a informaciones relativas a sus castigos, pero Ángel Gatica fundamenta su escapatoria en versículos de la Biblia, por lo que su huida tiene una aprobación de Cristo. Existe un miedo de toparse con los pecadores, el cual refleja el éxito de la información aplicada en las proclamas, representando que más que ser un miedo a la muerte misma, es una inseguridad a morir en manos de los enemigos del Rey.

$\mathrm{Ni}$ hablar de los realistas que piensan en unirse a las fuerzas patriotas. Las proclamas serán claras en su discurso, afirmando que además de traicionar al Rey, también se abandona la lucha de Jesucristo.

Al igual que la propaganda de Ángel Gatica, el padre Pedro Curiel escribe asociaciones bíblicas en sus proclamas, creando un discurso en donde los traidores realistas son ovejas descarriadas que han perdido el rumbo, encontrándose lejanas del liderazgo de su siervo:

"Esto es lo que deveis hacer, y espero que hagáis, y os lo suplico por la sangre de Jesucristo, cuyo Ministro soy aunque indigno, humillados y reconoced de nuevo por vuestro señor temporal a nuestro Soberano Fernando $7^{\circ}$, y como ovejas descarreadas volved á vuestro rebaño: ni os cause admiración que os hable en este lenguaje, por que en el mismo hecho de haberos revelado contra el Rey os haveis cegregado del rebaño de la Iglesia"14.

Mientras se desarrollaba una guerra por las armas, desde el ámbito de la escritura se efectuaba otra para ganar fieles que estuviesen dispuestos a entregar la vida por el Rey. Esta propaganda fue un mecanismo de control de la población, las cuales fundamentaban ideológicamente la pertenencia de la Monarquía con la religión cristiana. De esa forma:

“...la proclama se transforma en un instrumento propagandístico muy idóneo y recurrente que trata de excitar, a través de un lenguaje sutil y simbólico, los más profundos sentimientos de las gentes, un sentimiento patriótico, de pertenencia a una realidad histórica concreta, de pertenecía a una nación” (Mestre, 2011: 107).

\section{3. "Todo poder nos viene de Dios... y los soberanos (aunque estos sean tiranos como Nerón) la religión nos manda que les obedezcamos". La causa justa de Dios y del Rey: Castigo y defensa divina.}

"Son los reies los ungidos p.r el señor y su consagración es tanto más sagrada p.r q.e el mismo Dios determina el modo como se habían de consagrar las cabesas ó gefes de sus pueblos. La escritura nos dice, como mando a Samuel q.e eligiese a Saul, y le consagrare. Todo poder nos viene de Dios, dice S.n Pablo; y los soberanos (aunque estos sean tiranos como Nerón) la religión nos manda q.e les obedezcamos a imitación 
David Fuentes Acuña, "No le pido a Dios otra cosa que me quite la vida antes que yo vea a los patriotas".

Religión y miedo: las emociones de los últimos defensores realistas (1818-1822).

Autoctonía. Revista de Ciencias Sociales e Historia, Vol. I, N²

de los primeros cristianos q.e perecían con llanto, y rogaban por sus perseguidores (...) $\mathrm{Al}$ mismo Jesús vieron que subordinó a los q.e tenian la autoridad, y q.e jamas predico sino obediencia. Gobierna Dios el mundo aun siendo invisible; pero quiere q.e los reies, q.e son sus legitimos hagan suministrar la justicia en su nombre, y le representen 15 .

Esta proclama elaborada por el cura Luis José de Burañao, caracteriza a los reyes como los sujetos representativos del poder divino en la tierra, a diferencia de la idea revolucionaria que privilegia la elección de los pueblos a sus autoridades. A pesar de los errores que muchas veces pueden cometer los reyes, existe un poder que está por sobre todo y se debe respetar a toda costa. Al igual que Jesús, quien predicó el cumplimiento y respeto de sus autoridades, el realista debe ser un hombre de obediencia a la religión, lo cual trae consigo un sostenimiento de la Monarquía.

Esta asociación cristiano-político apela a un respeto sincero por el Rey católico, por lo que todo sujeto que no la acate será considerado un traidor desde lo público, pero un pecador desde lo religioso. Esta idea fue fundamentada por las proclamas en colaboración con la iglesia, quien se adhirió a la publicación de propaganda a través de sus representantes jerárquicos. Mestre afirma que las proclamas sirvieron como alianza entre la Monarquía y la iglesia, unión que viene inclusive desde 1809 con la invasión francesa a la península, en donde “...el peso de la religión en sus escritos era el principal argumento para llamar a los españoles a la sublevación contra el invasor francés" (Mestre, 2011: 109). Al igual que con los patriotas, considerados herejes por eliminar al Rey como autoridad central política, los franceses son descritos de la misma manera: "Llegó el momento, amados hijos míos, de ver a las puertas de nuestra Casa unos enemigos, que desconociendo la misma razón natural, ultrajan a su Dios" (Mestre, 2011: 109)16.

Otra proclama que seguirá los mismos lineamientos del cura Luis José de Burañao será la elaborada por Ángel Gatica. En ella aparece un miedo divino que caracteriza a Dios como seguridad, pero ante el hecho de traicionarlo, este se transforma en fuego consumidor. Como se menciona en la proclama:
"Si teneis todavía en vuestro corazón aquellos verdaderos sentimientos [ilegible] debéis temblar si por nuestra desgracia habeis caído en el fanatismo de los revolucionarios que con tanto descaro, se oponen a las disposiciones de los Reyes, alusionando para esto a los Ignorantes, que los Reyes deben ser autoridad a los Pueblos por la obediencia que les prestan. (...) Cuando por el contrario tenemos los apoyos más sólidos, más justos, y más firmes que nos acreditan deber de los reyes su autoridad al altísimo por cuanto reciben del mismo Dios su poder"117.

Como Dios aparece otorgando a los realistas un apoyo único en comparación con el sistema revolucionario, es un deber defender la causa del Rey, ya que de lo contrario se estaría contradiciendo la palabra de Dios. Por lo mismo, todo aquel que no defienda la causa realista es señalado como un traidor de la religión cristiana y, por eso, el cura Ángel Gatica, afirma que se debe temblar si se siguen a los revolucionarios. Se establece que si no se protege la causa del Rey, se está cayendo en un pecado religioso de traición, por lo que estos deben saber:

"...que inmediatamente haceis contra un dogma de fe, y principios de la religión oponiendose efectivamente a lo que se nos dice en la Sagrada Escritura la que nos hace ver cuanto es el cariño y respeto que debemos a la soberanía, de suerte dice que el que temerariamente se oponga a las autoridades legitimas se opone igualmente ala voluntad de Dios"18.

Las proclamas describen la palabra de Dios como única y verdadera, pero también como una ideología que, en el caso de no cumplirse, presentaría características claras de traición a la religión. Aquí lo analizamos como un miedo social aceptativo, ya que, según Mabel Moraña y su relación con el afecto, el miedo como emoción expresa modos de ser subjetivos, la cual conecta o divide individuos, resiste o favorece cambios sociales (Moraña, 2012: 326). Por eso mismo, ligado al afecto, muchos aceptan el miedo y otros, debido a la resistencia establecida desde arriba, temen acatarlo por las determinaciones de los altos mandos monárquicos. 
David Fuentes Acuña, "No le pido a Dios otra cosa que me quite la vida antes que yo vea a los patriotas".

Religión y miedo: las emociones de los últimos defensores realistas (1818-1822).

Autoctonía. Revista de Ciencias Sociales e Historia, Vol. I, N²

Aquí aparece el riesgo como un miedo al momento de aceptar las ideas patriotas en donde, según Korstanje, este es una convergencia de construcciones socio-culturales respecto a peligros y amenazas reales o imaginadas, hablando incluso de un "discurso del riesgo" (Korstanje, 2011: 4). El cura Gatica en su proclama, señala el riesgo de lo que significa seguir las banderas revolucionarias:

"De aquí que si la perfidia, el embuste o el temor de un gobierno ylegitimo, como los que exponen los Ynsurgentes ha podido influir en vosotros para que conoscais alguna distancia, o repugnancia ala justa causa del Rey, y ala devida obediencia de los que a su nombre mandan, tened entendido (ablo con toda clase de perdón) que inmediatamente haceis contra un dogma de fe, y principios de la religión oponiendose efectivamente a lo que se nos dice en la Sagrada Escritura la que nos hace ver cuanto es el cariño y respeto que debemos a la soberanía, de suerte dice que el que temerariamente se oponga a las autoridades legitimas se opone igualmente ala voluntad de Dios" 19 .

El riesgo, en este caso, es una construcción sociocultural que apela a las amenazas de un castigo divino. El riesgo es parte del miedo, siendo dual porque puede describir a los patriotas como asesinos enemigos de la religión católica, pero también puede caracterizar el miedo interno de los realistas por sentirse condenados al infierno. Esta será la otra cara de las proclamas realistas. Para motivar a la población a pelear por el Rey, más que atemorizarlas con los patriotas, también se debe establecer un miedo interno para los que sientan o deseen abandonar a la corona. Estamos en un contexto de constante guerra y, probablemente, también aparecieron realistas que privilegiaron la protección de su familia más que la defensa de un Rey que vive a miles de kilómetros. Por lo mismo, para que dichos defensores lo piensen dos veces, el abandono trae consecuencias eternas.

“...debéis temblar si por nuestra desgracia habeis caído en el fanatismo de los revolucionarios que con tanto descaro, se oponen a las disposiciones de los Reyes, alusionando para esto a los Ignorantes, que los Reyes deben ser autoridad a los Pueblos por la obediencia que les prestan"20.

Los revolucionarios al delegar el poder en el pueblo, están cayendo en el pecado de eliminar a la religión cristiana como la única capaz de entregar el poderío en los gobernantes. Esto es algo que no puede ser tolerado ni aceptado por los realistas. La proclama del Fray Pedro Curiel evidencia que muchos habitantes de la provincia de Cauquenes han aceptado las banderas patriotas y, por eso mismo, el cura se preguntará: “QQuién de estos pobres fieles de Cauquenes han perdido el juicio?” El sacerdote comenzará a criticar y amonestar a todos estos habitantes, señalándoles en la proclama que han pecado contra el mismo Dios.

"Ha si conoceréis tu villa de Cauquenes los males que te han de venir, tus enemigos te ajearán por todas partes y no dejarán piedra sobre piedra en tus edificios". También el Fray Pedro Curiel señalará preceptos ligados a la traición cristiana, muy parecida, inclusive, a los castigos que Dios establece a sus siervos en el antiguo testamento. Dios aparece como un fuego consumidor que castigará a los traidores del Rey católico:

"Si fieles míos; todos estos trabajos debéis esperar por que haveis abandonado el santo temor de Dios, os haveis rebelado contra vuestra Madre la Yglesia, y haveis levantado vandera contra nuestro soberano el señor D. Fernando $7^{\circ}$ y sinó decidme ¿Qué otros delitos mas que los vuestros cometió la Francia en nuestros días para verse como la haveis visto innundada y ajeada de Naciones asolados sus campos, incendiadas sus poblaciones y hecha axibutaria; la risa y mofa de las gentes, la Nación mas rica y poderosa del mundo? Pues si esto ha pasado a la Francia con tanto poder, con tanta plata, tanta tropa de mar y tierra, tantos navios y tantos aliados ¿Qué os pasará a vosotros que os hallais destituidos de todas estas cosas? No hay duda que ajearán vuestra villa los bárbaros Pehuenches, los llanistas, y los bravos costinos, pegarán fuego vuestras casas, se llevaran vuestros vienes, os pasaran vuestras lamas, y caminarán con vuestras mugeres é hijos, llevándolos aptivos"21. 
David Fuentes Acuña, "No le pido a Dios otra cosa que me quite la vida antes que yo vea a los patriotas".

Religión y miedo: las emociones de los últimos defensores realistas (1818-1822).

Autoctonía. Revista de Ciencias Sociales e Historia, Vol. I, N²

La proclama de Pedro Curiel es idéntica a varios versículos bíblicos en donde Dios envía profecías de castigo a los pecadores. No cabe duda que esa es la intención: la proclama es una copia bíblica, siendo un elemento de control ideológico que regula el orden tradicional conocido (Faundez y Cornejo, 2010). Eso también nos lleva a pensar en un estereotipo de fiel monárquico: personas cristianas, obedientes de los clérigos, conocedoras de las asociaciones monárquicas-católicas. Ante eso, es claro que cualquier persona que traicione al Rey, será castigada con los males del infierno.

Quizás por eso, muchos defensores realistas defendieron al Rey hasta la muerte, existiendo un estereotipo de persona claramente definido. Coffin señala sobre estos defensores, que no tienen: “... impuestos, ni carga, ni cosa alguna, por indigna que sea, que el pueblo no soporte gustoso si se le exige en nombre del Rey" (Coffin, 1898: 76).

Por lo mismo, los indígenas le preguntarán a John Coffin:

“...si los ingleses no son tributarios de España, si hay patriotas en Europa, esto es, si ha habido allí alguna nación que se haya atrevido a levantarse contra la autoridad del más católico de los reyes; y tal es, según me inclino a pensar, lo que en realidad se entiende por patriotismo en Chile" (Coffin, 1898: 149).

El guerrillero José María Marchant también entregará toda su disposición por la causa realista, evidenciando las asociaciones con la religión:

“...arriesgando la vida, que la miro como nada por mi rei i por mi lei... Y asi, señor, por la sangre real que corre por mis venas, por nuestro rei, por Jesucristo, me diga lo que hemos de hacer... Yo tengo perdida mi vida, i no perdono sacrificio por hacer..." (Barros Arana, 1892; Contador, 1998: 122).

Guillermo Reyes también asociará la lucha monárquica con la defensa divina, motivando a los habitantes de Cauquenes para que se unan a los ejércitos realistas, debido:

“...que aquella hera la ocasión en que se debían esmerar por servir sin reservar nada y servirle al rey hera lo mismo que servirle a Dios y que si la Patria les hiva hatacar devian rendir la ultima gota de sangre en contra de

\section{ellos" (Contador, 1998: 139) 22.}

No cabe duda que el estereotipo del fiel realista se asocia a Guillermo Reyes y José María Marchant. Hombres que arriesgan su vida por el Rey porque eso significa defender a Dios. Para ellos, la religión cristiana siempre está presente y es activa en la lucha que desarrollan, por lo cual, si Dios existe de manera constante en sus vidas, la opción del infierno también es verdadera, por mucho de23 que ellos la rechacen. Las proclamas buscan, de una u otra manera, recordarles a todos los fieles lo que les pasará si traicionan a su Rey y los premios que pueden conseguir en el caso de morir en su defensa.

Será tan grande la exacerbación y la pasión por la corona, que el viajero John Coffin, en un momento de análisis, llegó a la conclusión de no poder comprender la total sumisión de los habitantes sureños hacia una Monarquía que se encontraba a miles de kilómetros de la provincia de Concepción:

"Confieso que jamás hasta ahora había podido formarme una idea cabal de la mansa y degradante sumisión a que el despotismo y la ignorancia unidos pueden reducir al género humano. Que el Rey fuese absoluto señor de vidas y haciendas era hasta hace muy poco un axioma tan indiscutible entre ellos como que el Papa es jefe de la Iglesia, lo que nadie que desee vivir en paz, se atreverá hoy tampoco a dudar" (Coffin, 1898: 149-149).

Todo esto produjo un miedo que, según Korstanje, se transformó en un sentimiento humano básico que busca la supervivencia del cuerpo (Korstanje, 2011: 1). El miedo padecido por los realistas en relación a la religión, fue visto como una perspectiva de sobrevivencia en donde seguir la causa del rey es ganar la eternidad, pero traicionarla, es temer un castigo de cielo. De esa manera, el miedo se mueve en una dualidad de seguridad, pero siempre con el miedo presente de la traición. Así, el esfuerzo y el compromiso total a la causa como seguridad, se bate constantemente con el miedo de traicionar a la Monarquía y de terminar bañado de fuego en el infierno.

\section{Conclusiones}

La causa del rey, para los fieles realistas, fue vista dentro de una lógica de seguridad que, al parecer, tuvo una gran aceptación en la población penquista. 
David Fuentes Acuña, "No le pido a Dios otra cosa que me quite la vida antes que yo vea a los patriotas".

Religión y miedo: las emociones de los últimos defensores realistas (1818-1822).

Autoctonía. Revista de Ciencias Sociales e Historia, Vol. I, N²

John Coffin señalará, que “...excepto a través de las rejas de una prisión o sobre alguna lejana colina, declaro que jamás he visto un patriota declarado" (Coffin, 1898: 225). Este es un punto importante, ya que nos permite pensar en una provincia de Concepción que pudo contar con más adeptos a la causa del Rey.

Independiente del mayor fervor que pueda tener la causa del Rey, deducimos que los mapuches defendieron a la corona en búsqueda de sus propias pretensiones como pueblo, por lo que también podríamos hablar de sus propios miedos. Inseguridades ligadas a relacionarse con los patriotas, perder identidad territorial como pueblo, acabar con una estabilidad parlamentaria del último siglo, etc. Puntualmente, no encontramos documentación que asocie los miedos cristianos del grupo mapuche, salvo seguridades ligadas al Rey católico. De ahí que interpretemos sus inseguridades religiosas.

También determinamos que los campesinos si sintieron un miedo religioso con el fracaso del sistema monárquico. A pesar de eso, son utilizados como soldados de guerra por los altos mandos. De ahí la importancia de las proclamas: son discursos que implantan miedos, siendo impuestos y reforzados a la población para que no abandonen la lucha. Evidentemente, eso se pinta con la traición y la culpabilidad del infierno, más allá de si los altos mandos creían en eso o no.

Comprendimos que la religión es un elemento de control en la población, sobre todo en esos tiempos de guerra. Sin embargo, si pensamos de manera individual sobre los sujetos, estos perciben y aceptan sentimientos más allá de la religión. Ellos viven un contexto problemático de conflicto, buscando constantemente seguridades en sus vidas, por lo que la Monarquía representa la excusa perfecta del cual aferrarse. Esta seguridad realista se puede reflexionar según el concepto impulso afectivo trabajado por Mabel Moraña, en donde cada persona actúa según sus vivencias personales y del mismo contexto de la guerra, debiéndose a “...la subjetividad imperante en los sujetos, lo cual permite que exista una modificación del pasado, presente y futuro de la sociedad globalizada, la cual va relacionada con ciertas manifestaciones culturales y pasionales" (Moraña, 2012: 323). Pensamos esto en relación a nuevas emociones a estudiar durante este proceso; la pasión o el fanatismo podrían ser estudiados desde esta lógica, ya que la seguridad de los realistas, en muchos casos, es muy fervorosa. En esa lógica, ¿Qué pasa con los patriotas creyentes en Dios? ¿Se unieron a la causa real? ¿Cómo asociaron su propia defensa?

Esperamos que este sea un primer apronte para que, más que acercarnos a la Historia de las Emociones, nos permita estudiar a los chilenos que defendieron al Rey de España, los cuales han sido poco abordados por la historiografía.

\section{Referencias bibliográficas}

Fuentes Primarias

Archivo Bernardo O’Higgins:

Volumen XII

Archivo Nacional Histórico de Chile (ANHcH)

Fondo Ministerio de Guerra:

Volumen 52

Volumen 101

Volumen 16

Fondo Intendencia de Concepción

Volumen 6

Volumen 33

Fuentes Impresas

Bladh, C.D. (1951): La República de Chile. Santiago de Chile, Imprenta universitaria.

Coffin, J. (1898): Diario de un joven norte-americano: detenido en Chiloé durante el periodo revolucionario de 1817-1819. Santiago de Chile, Impr. Elzeviriana.

Puigmal, P. (2005): Memorias de Jorge Beauchef. Santiago, Centro de Investigaciones Diego Barros Arana.

\section{Bibliografía}

Barros Arana, D. (1850): Estudios Históricos sobre Vicente Benavides y las campañas del sur.1818-1822. Santiago, Impr. De Julio Belin y compañía.

Barros Arana, D. (1892): Historia Jeneral de Chile, Tomo XIII. Santiago, Rafael Jover Editor. 
David Fuentes Acuña, "No le pido a Dios otra cosa que me quite la vida antes que yo vea a los patriotas". Religión y miedo: las emociones de los últimos defensores realistas (1818-1822).

Autoctonía. Revista de Ciencias Sociales e Historia, Vol. I, N²

Bauman, Z. (2008): Miedo Líquido. La sociedad contemporánea y sus temores. Buenos Aires, Paidos.

Bengoa, J. (1985): Historia del Pueblo Mapuche. Santiago, Ediciones sur. Colección estudios históricos.

Collier, S. (1977): Ideas y política de la Independencia Chilena, 1808-1833. Santiago, Editorial Andrés Bello.

Contador, A. (1998): Los Pincheira: un caso de bandidaje social: Chile 1817-1832. Santiago, Bravo y Allende editores.

Cornejo, M y X. Faúndez (2010): “Aproximaciones al estudio de la transmisión transgeneracional del trauma psicosocial”. En Revista de Psicología, 19 (2), pp. 31-54.

Delumeau, J. (2002): "Miedos de ayer y de hoy". En Villa Martínez, M. I., ed., El miedo. Reflexiones sobre su dimensión Social y Cultural. Medellín, Corporación Región, pp. 9-21

Domínguez, V. (2003): "El Miedo en Aristóteles". En Psicothema, 15 (4), pp. 662-666.

Hobsbawm, E. (2001a): Bandidos. Barcelona, Editorial Crítica.

Hobsbawm, E. (2001b): Rebeldes Primitivos. Estudio sobre las formas arcaicas de los movimientos sociales en los siglos XIX y XX. Barcelona, Crítica.

Korstanje, M. (2011): "La Fobología, ¿Ciencia o forma de entretenimiento?", Nómadas. Revista crítica de Ciencias Sociales y Jurídicas, Universidad complutense, 31 (3), 16 pp.

León, L. (2010): Ni patriotas ni realistas. El bajo pueblo durante la Independencia de Chile. Santiago, Universidad de Chile.

Mestre, P. (2011): "El documento de la Proclama durante la Guerra de la Independencia: instrumento de adhesión patriótica y exaltación de la nación española”. En F, Iñesta y F, Mateos, coord. España, Nación y Constitución y otros estudios sobre Extremadura. Llerena, Sociedad Extremeña de Historia, pp. 105-115.

Moraña, M. (2012): "Postcriptum. El afecto en la caja de herramientas". En M. Moraña y I. Sánchez, ed., El lenguaje de las emociones. Afecto y cultura en América Latina. Madrid, Editorial Iberoamericana, pp. 313-337.

Page, C. (2004): "Las proclamaciones reales en Córdoba del Tucumán”. Revista Complutense de Historia de América, 30, pp. 77-94.

Philippe, R. (2006): "Seguridad objetiva y seguridad subjetiva". Revista Catalana de Seguretat Pública, 16, pp. 91-102.

Plamper, J. (2014): Historia de las Emociones: Caminos y retos. London, Goldsmiths.

Salazar, G. (2011) Construcción del Estado en Chile. (18001837) Democracia de los pueblos, militarismo ciudadano, golpismo oligárquico. Santiago, Editorial Sudamericana.

Timmermann, F. (2005): El factor Pinochet: Dispositivos de poder- Legitimación- Elites. Chile, 1973-1980. Santiago, Ediciones Universidad Católica Silva Henríquez.

Timmermann, F. (2015): El Gran Terror. Miedo, emoción y discurso. Chile, 1973-1980. Santiago, Ediciones Copygraph.

Vicuña Mackenna, B. (1972): La Guerra a Muerte, Santiago, Editorial Francisco de Aguirre.

Recibido: 31 de marzo de 2017. Aceptado: 5 de julio de 2017.

\section{Notas}

1 "Freire a O'Higgins", (Concepción, 27 de enero de 1819). En Archivo Bernardo O'Higgins (ABO), vol. XII, 66.

$2 \quad$ Los dos autores analizan la Guerra a Muerte desde la subjetividad. Los patriotas son los hombres civilizados y los realistas expresan la barbarie.

3 “Gazeta Ministerial” (13 de febrero de 1819).

4 "Proclama de Angel gatica a los habitantes de Chillán", (s/f). En ANMG, vol. 101, f, 97-98.

$5 \quad$ "Instrucciones de Benavides a sus tropas reales", (Cuartel General de Arauco, 27 de agosto de 1819). En AMNG, vol. 52, f. 184.

6 "Freire a O’Higgins", (Concepción, 23 de septiembre de 1820). En ANIC, vol. 6, f, 104.

7 "Freire a O'Higgins", (Chillán, 14 de enero de 1819), En ANIC, Vol. 6, f, 3 .

8 "Reglamento para los oficiales prisioneros que viajan rumbo a Mendoza", (14 de abril de 1818). En ANMG, vol. 16, f. 294

9 "Proclama de Juan Antonio Ferrebú a los habitantes de Rere", (Santa Juana, 5 de septiembre de 1820). En ANMG, vol. 101, f, 4 .

10 "Gazeta Ministerial Extraordinaria”, (4 de marzo de 1819).

11 "Freire a O’Higgins", (Chillán, 14 de enero de 1819), En ANIC, Vol. 6, f, 3 .

12 “Maria Casilda Ortega”. (El Rosal, 14 de octubre de 1820) En ANMG, vol. 101, f. 23-24.

13 "Proclama de Angel gatica a los habitantes de Chillán", (s/f). En ANMG, vol. 101, f, 97.

14 "Proclama de Fray Pedro Curiel a la villa de Cauquenes". (s/f). En ANMG, vol. 101, f. 95-96. 
David Fuentes Acuña, "No le pido a Dios otra cosa que me quite la vida antes que yo vea a los patriotas".

Religión y miedo: las emociones de los últimos defensores realistas (1818-1822).

Autoctonía. Revista de Ciencias Sociales e Historia, Vol. I, N²

15 "Proclama de Luis José de Burañao", (Colileu, 9 de octubre de 1820). En ANMG, vol. 101, f. 42

16 AHN. Diversos-Colecciones, 85, n5. "Proclama del obispo de orihuela al pueblo de Valencia”, en (Mestre, 2011: 109).

17 "Proclama de Angel gatica a los habitantes de Chillán", (s/f). En ANMG, vol. 101, f, 97.

18 "Proclama de Angel gatica a los habitantes de Chillán", (s/f). En ANMG, vol. 101, f, 97.

19 "Proclama de Angel gatica a los habitantes de Chillán", (s/f). En ANMG, vol. 101, f, 97.

20 "Proclama de Angel gatica a los habitantes de Chillán", (s/f). En ANMG, vol. 101, f, 97.

21 "Proclama de Fray Pedro Curiel a la villa de Cauquenes". (s/f). En ANMG, vol. 101, f. 95-96.

22 "Causa contra Guillermo Reyes", (Cauquenes, 1821). En AJ, cauq, leg. 102, N4. También en (Contador, 1998: 139) 